\title{
Avaliação de ácidos orgânicos em dietas para leitões de 21 a 49 dias de idade ${ }^{1}$
}

\section{Letícia Silva de Freitas ${ }^{2}$, Darci Clementino Lopes ${ }^{3}$, Ary Ferreira de Freitas ${ }^{4}$, Jailton da Costa Carneiro ${ }^{4}$, Anderson Corassa ${ }^{2}$, Sérgio de Miranda Pena ${ }^{5}$, Leidimara Feregueti Costa ${ }^{5}$}

\author{
1 Parte da dissertação de Mestrado da primeira autora. Trabalho parcialmente financiado pela empresa METACHEM \\ 2 Doutorando em Zootecnia - Universidade Federal de Viçosa, DZO - UFV, Viçosa, MG, 36571-000. Bolsista da CAPES. \\ 3 Universidade Federal de Viçosa, DZO - UFV, Viçosa - MG, 36571-000. \\ ${ }^{4}$ Embrapa, Gado de Leite - Juiz de Fora - MG, 36038-330. \\ ${ }^{5}$ Mestrando em Zootecnia - Universidade Federal de Viçosa, DZO - UFV, Viçosa, MG, 36571-000.
}

RESUMO - Objetivou-se estudar os efeitos da proporção crescente de ácidos orgânicos na dieta sobre o desempenho e a incidência de diarréia em leitões no período de 21 a 49 dias de idade. Os tratamentos foram constituídos de uma dieta basal e três dietas suplementadas com 0,$78 ; 0,84$; e $0,90 \%$ (21 a 35 dias de idade) e 0,$59 ; 0,63$; e $0,66 \%$ ( 36 a 49 dias de idade) de ácidos orgânicos à base de ácido láctico. Avaliaram-se o consumo de ração médio diário (CRMD), o ganho de peso médio diário (GPMD), a conversão alimentar (CA) e o escore fecal dos leitões. O CRMD e o GPMD não variaram entre as proporções de ácidos orgânicos nos períodos avaliados. A CA dos leitões que receberam $0,84 \%$ de ácidos orgânicos foi melhor que a daqueles que receberam as dietas basal e com $0,90 \%$ de ácido no período de 21 a 35 dias. Os leitões que receberam $0,84 \%$ de ácidos apresentaram menor escore fecal em relação aos alimentados com $0,90 \%$. Amostras de sangue foram coletadas para dosar a concentração plasmática de ácido láctico de leitões aos 35 dias. A concentração de ácido láctico dos animais que receberam 0,90\% de ácido aumentou em 60,61\% em relação à do grupo da dieta basal. Isolaram-se bactérias das fezes dos animais para identificação de microrganismos. As proporções de 0,84 e $0,63 \%$ de ácidos orgânicos, respectivamente, nas fases de 21 a 35 e de 36 a 49 dias foram mais eficientes, considerando-se que não foram isoladas as bactérias E. coli a-hemólise e Streptococcus sp. A utilização de $0,84 \%$ de ácidos orgânicos na dieta proporcionou melhor conversão alimentar no período de 21 a 35 dias de idade e melhor consistência de fezes e controle de E. coli a-hemólise e Streptococcus sp com a suplementação de $0,84 \%$ de ácidos no período de 21 a 35 dias e de $0,63 \%$ no período de 36 a 49 dias.

Palavras-chave: creche, ácido láctico, diarréia

\section{Effects of feeding organic acids for piglets from 21 to 49 days old}

ABSTRACT - The effects of feeding increasing dietary organic acids on performance and diahrrea incidencefor piglets from 21 to 49 days old were evaluated. The treatments were constituted of a basal diet and three groups supplemented with $0.78,0.84$ and $0.90 \%$ of organic acids in the 21 to 35 days period and $0.59,0.63$ and $0.66 \%$ in the 36 to 49 days period, basedoin lactic acid. Average daily feed intake (ADFI), average daily weight gain (ADWG), feed:gain ratio (F/G) and diarrhea scores were evaluated. The ADFI and the ADWG did not differ among the organic acids proportions in the evaluated periods. The FCR of piglets fed diet with $0.84 \%$ of organic acids was better than those fed basal and $0.90 \%$ diets, in the 21 to 35 days period. The piglets fed diet with $0.84 \%$ of organic acids showed lower diarrhea score than those fed $0.9 \%$. Blood samples were collected to dose lactic acid concentration in plasma of piglets at 35 days old. The plasma lactic acid concentration of the animals fed diet with $0.90 \%$ of acid increased $60.61 \%$ in relation to the basal diet. Bacterias were isolated from animals feces to microorganisms identification. The 0.84 and $0.63 \%$ organic acids proportion, in the period form 21 to 35 days and from 36 to 49 days old, respectively, were more efficient considering that the E. coli a-hemolytic and Streptococcus sp bacterias was not isolated. The $0.84 \%$ organic acids level in the piglet diets provide better F/G in the period from 21 to 35 days old and better diarrhea score and E. coli a-hemolytic and Streptococcus sp control supplementing $0.84 \%$ of acids in the period from 21 to 35 days old and $0.63 \%$ from 36 to 49 days.

Key Words: diarrhea, lactic acid, nursery

\section{Introdução}

A fase pós-desmame de suínos tem representado um desafio considerável para o criador, tendo em vista a perda econômica com as altas taxas de morbidade e mortalidade, atribuídas principalmente à diarréia pós-desmame e à doença do edema (Pluske et al., 1997; Tsiloyiannis et al., 2001a). 
A insuficiência de enzimas digestivas nessa fase de desenvolvimento dos leitões resulta em baixa digestão dos nutrientes (Corassa et al., 2006) e, conseqüentemente, aumenta a osmolaridade do conteúdo do trato digestivo, provocando diarréia osmótica. Os nutrientes não absorvidos são substratos para cepas de Escherichia coli (E. coli), favorecendo sua colonização, que resulta no aparecimento de diarréia infecciosa (Tzipori et al., 1980) e causa o encurtamento da vilosidade, o aumento da profundidade de cripta e do turnover dos enterócitos e, segundo Pluske et al. (1995), reduz a atividade das enzimas localizadas na borda da escova dos enterócitos, região mais afetada do vilo.

As conseqüências dessas alterações indicam a necessidade de alternativas viáveis que minimizem os principais problemas da indústria suinícola moderna. Em razão da crescente exigência de órgãos de saúde mundiais e de países importadores da carne suína brasileira, alguns aditivos têm sido testados na busca de uma alternativa com eficiência próxima à dos antibióticos, os quais resultam em resistência das bactérias que podem afetar tanto os animais quanto os homens (Corassa et al., 2006).

A resposta dos animais pode ser melhorada com a suplementação com ácidos orgânicos (Jensen, 1998), que vêm sendo apontados como estratégia nutricional eficiente (Partanen \& Mroz, 1999; Tsiloyiannis et al., 2001a). A suplementação de dietas com ácidos orgânicos, ou seus sais, tem reduzido a freqüência de diarréia e melhorado o desempenho de leitões (Knarreborg et al., 2002), têm prevenido a doença do edema pós-desmame (Thomlinson \& Lawrence, 1981) e controlado o desenvolvimento da E. coli (Presser et al., 1997; Tsiloyiannis et al., 2001a),

O ácido láctico é de cadeia curta e, por ser fraco, pode estar entre os ácidos mais efetivos disponíveis no mercado na prevenção de doenças (Partanen \& Mroz, 1999). Os ácidos fracos têm maior atividade antimicrobiana no estômago (Canibe et al., 2001; Knarreborg et al., 2002), pois, com sua constante de ionização $\left(\mathrm{p} K_{\mathrm{a}}\right)$ relativamente maior, apresentam-se em maior concentração na forma não-ionizada. $O$ ácido não-ionizado se difunde através da membrana da bactéria (Presser et al., 1997; Partanen \& Mroz, 1999; Roth, 2000; Canibe et al., 2001; Silva, 2004; Gravesen et al., 2004; Halm et al., 2004) e, em seu interior, dissocia-se (Dean \& Lange, 1985; Halm et al., 2004), causando acidificação do citossol (Gravesen et al., 2004), comprometimento da atividade celular e morte da bactéria.

A ação mais efetiva dos ácidos é provavelmente a atividade antimicrobiana, além da modificação da flora intestinal (Burnell et al., 1988), mediante a produção de um meio favorável para bactérias lácticas (Tsiloyiannis et al., 2001a), que promovem benefícios ao organismo do animal e podem, também, causar queda de pH no lúmen intestinal (Giesting \& Easter, 1985; Risley et al., 1991; Partanen \& Mroz, 1999; Santos et al., 2003).

Diante do exposto, propôs-se neste trabalho avaliar os efeitos da proporção crescente de ácidos orgânicos na dieta sobre o desempenho e a incidência de diarréia de leitões no período de 21 a 49 dias de idade.

\section{Material e Métodos}

O experimento foi conduzido no Setor de Suinocultura do Departamento de Zootecnia da Universidade Federal de Viçosa, em Viçosa, MG, no período de maio a julho de 2004.

Foram utilizados 128 leitões, de ambos os sexos, desmamados aos 21 dias de idade, em um delineamento experimental de blocos ao acaso, com quatro tratamentos com diferentes proporções de ácidos orgânicos, oito repetições e quatro animais por unidade experimental. Foram adotados o peso e o parentesco dos leitões como critérios na formação dos blocos.

O experimento foi dividido em dois períodos, 21 a 35 dias e 36 a 49 dias de idade, nos quais foram utilizadas dietas à base de milho e farelo de soja, formuladas para atender às exigências nutricionais dos animais de acordo com recomendações de Rostagno et al. (2000). Em cada fase, os tratamentos foram constituídos por dietas isoprotéicas, isoenergéticas e isolisínicas. As composições centesimais e nutricionais das dietas basais nas duas fases estão apresentadas nas Tabelas 1 e 2 .

Em substituição ao amido, foram adicionadas às dietas nas dietas misturas de ácidos orgânicos, constituídas principalmente de ácido láctico. As composições das misturas (\%) utilizadas foram: mistura 1: 50 de ácido láctico, 10 de ácido fórmico e 5 de ácido fosfórico; mistura 2: 55 de ácido láctico, 10 de ácido acético e 5 de ácido fosfórico; e mistura 3: 48 de ácido láctico, 7 de ácido fórmico e 5 de ácido fosfórico.

As proporções de ácidos orgânicos das dietas experimentais foram 0,$78 ; 0,84 ;$ e $0,90 \%$ e 0,$59 ; 0,63 ;$ e $0,66 \%$, nos períodos de 21 a 35 dias e de 36 a 49 dias de idade, respectivamente. A dieta basal foi constituída de $0 \%$ de ácidos orgânicos. Os níveis de inclusão das misturas e as proporções de ácidos orgânicos nas dietas experimentais nos diferentes períodos estão apresentados na Tabela 3.

$\mathrm{O}$ pH da digesta no estômago foi determinado na Embrapa Gado de Leite, em Juiz de Fora, MG, utilizando-se Papel Indicador Especial com faixa de $\mathrm{pH}$ 2,5-4,5 (Merck). O papel indicador requer apenas o simples contato da amostra com a tira, indicando o pH do conteúdo pela alteração da coloração da tira. 
Tabela 1 - Composição percentual das dietas basais para leitões na fase de creche

Table 1 - Ingredient composition of the basal diets for piglets in the nursery phase

\begin{tabular}{|c|c|c|}
\hline \multirow[t]{2}{*}{$\begin{array}{l}\text { Ingrediente } \\
\text { Ingredient }\end{array}$} & \multicolumn{2}{|c|}{$\begin{array}{l}\text { Período } \\
\text { Period }\end{array}$} \\
\hline & $\begin{array}{l}21 \text { a } 35 \text { dias } \\
21 \text { to } 35 \text { days }\end{array}$ & $\begin{array}{l}36 \text { a } 49 \text { dias } \\
36 \text { to } 49 \text { days }\end{array}$ \\
\hline $\begin{array}{l}\text { Milho } \\
\text { Corn }\end{array}$ & 27,900 & 40,500 \\
\hline $\begin{array}{l}\text { Milho pré-cozido } \\
\text { Pre-cooked corn }\end{array}$ & 15,000 & 9,500 \\
\hline $\begin{array}{l}\text { Farelo de soja } 45 \% \\
\text { Soybean meal }\end{array}$ & 17,000 & 17,800 \\
\hline $\begin{array}{l}\text { Soro de leite em pó } \\
\text { Dried whey milk }\end{array}$ & 9,500 & 5,500 \\
\hline $\begin{array}{l}\text { Leite desnatado em pó } \\
\text { Skim dried milk }\end{array}$ & 10,000 & 7,500 \\
\hline $\begin{array}{l}\text { Açúcar } \\
\text { Sugar }\end{array}$ & 6,000 & 6,000 \\
\hline $\begin{array}{l}\text { Farinha de peixe } 55 \% \\
\text { Fish meal }\end{array}$ & 3,450 & 2,500 \\
\hline $\begin{array}{l}\text { Plasma sangüíneo } \\
\text { Blood plasm }\end{array}$ & 5,000 & 5,000 \\
\hline $\begin{array}{l}\text { Óleo de soja } \\
\text { Soybean oil }\end{array}$ & 1,450 & 1,100 \\
\hline $\begin{array}{l}\text { Calcário } \\
\text { Limestone }\end{array}$ & 0,441 & 0,510 \\
\hline $\begin{array}{l}\text { Fosfato monobicálcico } \\
\text { Mono-dicalcium phosphate }\end{array}$ & 0,800 & 0,980 \\
\hline $\begin{array}{l}\text { Sal comum } \\
\text { Salt }\end{array}$ & - & 0,050 \\
\hline $\begin{array}{l}\text { L-lisina } \mathrm{HCl}(79 \%) \\
\text { L-lysine } \mathrm{HCl}\end{array}$ & 0,496 & 0,390 \\
\hline $\begin{array}{l}\text { DL-metionina }(99 \%) \\
\text { DL-methionine }\end{array}$ & 0,256 & 0,039 \\
\hline $\begin{array}{l}\text { L-treonina } \\
\text { L-threonine }\end{array}$ & 0,129 & 0,112 \\
\hline L-triptofano & 0,068 & 0,009 \\
\hline $\begin{array}{l}\text { L-thryptophan } \\
\text { Cloreto de colina }\end{array}$ & 0,035 & 0,035 \\
\hline $\begin{array}{l}\text { Choline chlorine } \\
\text { Mistura vit. }+ \text { aditivos }{ }^{1} \\
\text { Vitamin mix }\end{array}$ & 0,100 & 0,100 \\
\hline $\begin{array}{l}\text { Mistura mineral } \\
\text { Mineral }\end{array}$ & 0,100 & 0,100 \\
\hline $\begin{array}{l}\text { Óxido de zinco } \\
\text { Zinc oxide }\end{array}$ & 0,300 & 0,300 \\
\hline BHT & 0,010 & 0,010 \\
\hline $\begin{array}{l}\text { Amido } \\
\text { Starch }\end{array}$ & 1,965 & 1,965 \\
\hline
\end{tabular}

${ }^{1}$ Conteúdo/kg de ração (Content/kg of diet): vit. A - 6.000 UI; vit. $D_{3}-1.500$ UI; vit. E -15 UI; vit. $\mathrm{K}_{3}-1,5 \mathrm{mg}$; vit. $\mathrm{B}_{1}-1,35 \mathrm{mg}$; vit. $\mathrm{B}_{2}-4 \mathrm{mg}$; vit. $B_{6}-2 \mathrm{mg}$; vit. $B_{12}-20 \mathrm{mg}$; ácido fólico (folic acid) $-0,75 \mathrm{mg}$; ácido nicotínico (nicotinic acid) - $20 \mathrm{mg}$; ácido pantotênico (pantothenic acid) 9,35 mg; biotina (biotin) - 0,08 mg; e Se - 0,300 mg.

2 Conteúdo/kg de ração (Content/kg of diet): $\mathrm{Fe}-100 \mathrm{mg}$; Cu - $10 \mathrm{mg}$; Co $1 \mathrm{mg}$; Mn - 40 mg; Zn - 100 mg; e I - 1,5 mg.

Após a desmama, os animais foram transportados para a sala de creche, de alvenaria, com piso de concreto, forro de madeira rebaixado, janelas de vidro tipo basculante, dotada de gaiolas metálicas e suspensas, medindo 1,60 x 1,0 x 0,56 m, com piso em plástico expandido e laterais de tela metálica, equipadas comcomedouros semi-automáticos,
Tabela 2 - Composição nutricional das dietas basais para leitões na fase de creche

Table 2 - Nutritional composition of the basal diets for piglets in the nursery phase

\begin{tabular}{|c|c|c|}
\hline \multirow[t]{2}{*}{$\begin{array}{l}\text { Nutriente } \\
\text { Nutrient }\end{array}$} & \multicolumn{2}{|c|}{$\begin{array}{l}\text { Período } \\
\text { Period }\end{array}$} \\
\hline & $\begin{array}{l}21 \text { a } 35 \text { dias } \\
21 \text { to } 35 \text { days }\end{array}$ & $\begin{array}{l}36 \text { a } 49 \text { dias } \\
36 \text { to } 49 \text { days }\end{array}$ \\
\hline $\begin{array}{l}\text { E. metabolizável }(\mathrm{kcal} / \mathrm{kg}) \\
\text { Metabolizable energy }\end{array}$ & 3,383 & 3,359 \\
\hline $\begin{array}{l}\text { Proteína bruta }(\%) \\
\text { Crude protein }\end{array}$ & 21,99 & 20,85 \\
\hline Lactose $(\%)$ & 12,12 & $\begin{array}{l}7,875 \\
1,598\end{array}$ \\
\hline $\begin{array}{l}\text { Lisina total }(\%) \\
\text { Total lysine }\end{array}$ & & \\
\hline $\begin{array}{l}\text { Lisina digestível (\%) } \\
\text { Digestible lysine }\end{array}$ & 1,199 & 1,062 \\
\hline $\begin{array}{l}\text { Metionina digestível (\%) } \\
\text { Digestible methionine }\end{array}$ & 0,372 & 0,280 \\
\hline $\begin{array}{l}\text { Treonina digestível (\%) } \\
\text { Digestible threonine }\end{array}$ & 0,779 & 0,624 \\
\hline $\begin{array}{l}\text { Triptofano digestível (\%) } \\
\text { Digestible thryptonphan }\end{array}$ & 0,234 & 0,170 \\
\hline $\begin{array}{l}\text { Fósforo disponível (\%) } \\
\text { Available phosphorus }\end{array}$ & 0,524 & 0,478 \\
\hline $\mathrm{Ca}(\%)$ & 0,799 & 0,752 \\
\hline $\mathrm{Na}(\%)$ & 0,284 & 0,257 \\
\hline
\end{tabular}

bebedouros tipo chupeta e lâmpadas de calor $(250 \mathrm{~W})$ dispostas à altura dos animais para promover o aquecimento dos leitões.

Durante o período experimental, um termômetro de máxima e mínima foi colocado em uma gaiola vazia no centro da sala à altura dos animais, para monitoramento do ambiente e registro diário das temperaturas (às $8 \mathrm{~h}$ ). Não foram realizadas a desinfecção e a limpeza diária da sala. A limpeza foi feita somente por meio de varrição, com a finalidade de aumentar o desafio.

Para avaliação do desempenho, foram calculados o consumo de ração médio diário (CRMD), o ganho de peso médio diário (GPMD) e a conversão alimentar (CA). A mensuração desses parâmetros foi realizada por meio da pesagem dos animais e comedouros no início do experimento e no final de cada período ( 35 e $49^{\circ}$ dias). Os controles do consumo e do desperdício das rações foram feitos diariamente. A conversão alimentar foi calculada pela relação do consumo com o ganho.

Os animais foram observados diariamente, para avaliação da consistência das fezes, utilizando-se o escore: 1 - fezes duras e firmes; 2 - fezes de consistência normal; 3 - fezes pastosas não-diarréicas; e 4 - fezes aquosas, características de quadro diarréico.

Foi realizado exame bacteriológico, por meio do isolamento de bactérias das fezes dos animais, para identificação dos possíveis microrganismos presentes no ambiente. 
Tabela 3 - Níveis de inclusão das misturas e proporção de ácidos orgânicos na dieta de leitões nos diferentes períodos na fase de creche Table 3 - Mixture inclusion levels and organic acids proportion in the diets of piglets at different periods in the nursery phase

\begin{tabular}{|c|c|c|c|c|}
\hline \multirow[t]{2}{*}{$\begin{array}{l}\text { Mistura }{ }^{1} \\
\text { Mixture }\end{array}$} & \multicolumn{2}{|c|}{$\begin{array}{l}\text { Nível de inclusão das misturas na dieta (\%) } \\
\text { Diet mixture inclusion level }\end{array}$} & \multicolumn{2}{|c|}{$\begin{array}{l}\text { Proporção de ácidos orgânicos na dieta }(\%) \\
\text { Organic acids proportion in the experimental diet }\end{array}$} \\
\hline & $\begin{array}{l}21 \text { a } 35 \text { dias } \\
21 \text { to } 35 \text { days }\end{array}$ & $\begin{array}{l}36 \text { a } 49 \text { dias } \\
36 \text { to } 49 \text { days }\end{array}$ & $\begin{array}{l}21 \text { a } 35 \text { dias } \\
21 \text { to } 35 \text { days }\end{array}$ & $\begin{array}{l}36 \text { a } 49 \text { dias } \\
36 \text { to } 49 \text { days }\end{array}$ \\
\hline Basal & 0,0 & 0,0 & 0,00 & 0,00 \\
\hline $\mathrm{B}+$ mistura 1 & 1,2 & 0,9 & 0,78 & 0,59 \\
\hline $\mathrm{B}+$ mistura 2 & 1,2 & 0,9 & 0,84 & 0,63 \\
\hline
\end{tabular}

${ }^{1}$ Mistura de ácidos orgânicos (organic acids blend) (\%): 1: 50 de ácido láctico (lactic acid), 10 de ácido fórmico (formic acid) e 5 de ácido fosfórico (phosphoric acid); 2: 55 de ácido láctico (lactic acid), 10 de ácido acético (acetic acid) e 5 de ácido fosfórico (phosphoric acid); 3: 48 de ácido láctico (lactic acid), 7 de ácido fórmico (formic acid) e 5 de ácido fosfórico (phosphoric acid).

Coletaram-se as fezes de todas as gaiolas em um único dia, ressaltando-se que havia gaiolas do período de 21 a 35 e de 36 a 49 dias. As amostras foram acondicionadas em saco plástico por tratamento, realizando-se um pool de amostras, que foram enviadas ao Laboratório Microvet, em Viçosa, MG, onde foi realizado o exame.

Após a pesagem, no $35^{\circ}$ dia, os animais foram submetidos a um jejum de 12 horas e, no $36^{\circ}$ dia, às $7 \mathrm{~h}$, foi coletado o sangue de um animal por gaiola (aquele que teve peso mais próximo da média da repetição), totalizando oito amostras por tratamento, para a dosagem de ácido láctico no plasma sangüíneo. O sangue foi acondicionado e identificado em tubos contendo anticoagulante fluoretado (duas gotas de fluoreto) e, em seguida, foi centrifugado e refrigerado, para permanecer estável em até seis dias, e então, enviado para o Laboratório Hermes Pardini, em Belo Horizonte, MG, para as devidas análises.

O plasma sangüíneo foi analisado pelo método enzimático utilizando-se para a dosagem de lactato o aparelho Advia 1650 (Bayer), ajustado para o comprimento de onda de $546 \mathrm{~nm}$, caminho óptico $1 \mathrm{~cm}$, e temperatura entre 20 e $37^{\circ} \mathrm{C}$, pela utilização do kit Lactato (Biosys). Foram preparadas duas misturas para cada tratamento e cada repetição para calibração do equipamento e cálculo da dosagem do ácido láctico: uma com $20 \mathrm{~mL}$ de soluçãopadrão e $2.000 \mathrm{~mL}$ de reagente e a outra com $20 \mathrm{~mL}$ de amostra e $2.000 \mathrm{~mL}$ de reagente. Após cinco minutos de incubação, foi medida a absorbância das amostras e da solução-padrão. O cálculo da concentração de lactato em $\mathrm{mg} / \mathrm{dL}$ está apresentado a seguir:

$$
\text { Lactato }(\mathrm{mg} / \mathrm{dL})=\frac{\Delta \mathrm{E} \text { Amostra }}{\Delta \mathrm{E} \text { Padrão }} \times 30 \text { (Padrão) }
$$

O reagente utilizado foi composto de Tris $\mathrm{pH} 7,5 ; 2,4,6$ tribromo-3-ácido hidroxibenzóico; lactato oxidase; peroxidase; e p-Aminoantipirina. A enzima lactato oxidase catalisa a reação de lactato para piruvato e dá origem a um cromógeno proporcional à concentração de lactato.

Os animais receberam alimentação à vontade durante três horas e meia de alimentação após a coleta de sangue e, em seguida, foram abatidos. Amostras de digesta foram coletadas no estômago, no duodeno, na porção média do jejuno e no íleo, para realizar a dosagem do ácido lático. As amostras foram acondicionadas e identificadas, submetidas a nitrogênio líquido no momento da coleta e mantidas congeladas em freezer a $-20^{\circ} \mathrm{C}$, para posterior análise.

As análises do ácido lático foram realizadas no Laboratório de Análise de Alimentos da Embrapa Gado de Leite, em Juiz de Fora, MG, utilizando-se o processo de cromatografia gasosa. As amostras foram descongeladas em temperatura ambiente para serem preparadas, usando-se a acetona 99,9\% (grau HPLC) como solvente. Foi extraído $1 \mathrm{~g}$ de cada amostra, que foi pesada em balança analítica e devidamente identificada e, em seguida, adicionada de $2 \mathrm{~mL}$ de acetona, permanecendo em repouso por 90 minutos, mas com agitação de um minuto em intervalos de 30 minutos. $\mathrm{O}$ extrato obtido foi transferido para tubos de Ependorf e centrifugado a $10.000 \mathrm{rpm}$ por 10 minutos, sendo o sobrenadante recolhido em "vials" e armazenado em refrigeração até a análise. As amostras preparadas foram injetadas no cromatógrafo, coluna DB-Wax $30 \mathrm{~m}$ comp. $\mathrm{x} 0,25 \mathrm{~mm}$ D.I x 0,25 mícron de filme, com o gás de arraste hidrogênio 4,7 FID, com vazão de $1,5 \mathrm{~mL} / \mathrm{min}$ (fluxo constante). Inicialmente, a temperatura do forno foi de $100^{\circ} \mathrm{C}$ durante 4 minutos (com uma rampa de aquecimento de $15^{\circ} \mathrm{C} / \mathrm{min}$ ), de $185^{\circ} \mathrm{C}$ durante 4 minutos e de $230^{\circ} \mathrm{C}$ durante 1 minuto. Após esse processamento, a temperatura do forno permaneceu em $235^{\circ} \mathrm{C}$ por 5 minutos, para limpeza da coluna.

Os dados de desempenho, de escore fecal e de concentração de ácido láctico no sangue e no trato digestivo foram submetidos à análise de variância pelo programa de análise estatística Statistical Analysis System (SAS, 1999) utilizando-se o peso inicial dos animais como co-variável; 
as médias foram comparadas pelo teste Duncan a $5 \%$ de probabilidade. $\mathrm{O}$ modelo estatístico adotado para as análises foi:

$$
\mathrm{Y}_{\mathrm{ijk}}=\mu+\mathrm{T}_{\mathrm{i}}+\mathrm{B}_{\mathrm{j}}+\beta_{1}\left(\mathrm{P}_{\mathrm{ijk}}-\overline{\mathrm{P}}\right)+\beta_{2}\left(\mathrm{P}_{\mathrm{ijk}}-\overline{\mathrm{P}}\right)^{2}+\varepsilon_{\mathrm{ijk}}
$$

em que: $Y_{i j k}=$ observação das características estudadas relativas ao tratamento i no bloco $\mathrm{j} ; \mu=$ média geral; $\mathrm{T}_{\mathrm{i}}=$ efeito do tratamento; $\mathrm{B}_{\mathrm{j}}=$ efeito do bloco; $\mathrm{P}_{\mathrm{ijk}}=$ efeito do peso inicial; $\beta_{1}$ e $\beta_{2}=$ coeficientes de regressão linear e quadrático da variável $Y_{\mathrm{ijk}}$, em função do peso inicial dos leitões; e $\varepsilon_{\mathrm{ijk}}=$ efeito dos fatores não controlados.

\section{Resultados e Discussão}

As temperaturas máxima e mínima medidas durante os períodos de 21 a 35 e de 36 a 49 dias de idade foram, respectivamente, $26 \pm 1,19$ e $22 \pm 1,07$, e $25 \pm 1,07$ e $21 \pm 1,97$. A temperatura ambiente é o componente climático de maior influência na produção animal (Curtis, 1983). Assim, o ambiente térmico no qual o suíno é mantido pode influenciar o consumo de alimento, a taxa, a eficiência e a composição do ganho e, conseqüentemente, o crescimento de leitões (Orlando et al., 2001).

Os resultados de consumo de ração médio diário (CRMD), ganho de peso médio diário (GPMD) e a conversão alimentar (CA) dos leitões nas fases de 21 a 35, 36 a 49 e 21 a 49 dias de idade, bem como o peso corporal, encontram-se na Tabela 4.

O CRMD e o GPMD não diferiram entre as proporções de ácidos orgânicos nos períodos avaliados. Entretanto, no período de 21 a 35 dias, os leitões que receberam as proporções de 0,78 e $0,84 \%$ de ácidos orgânicos na dieta apresentaram GPMD 13,53 e 14,49\% maior, em valor absoluto, em relação à dieta basal, respectivamente.

As proporções de ácidos orgânicos influenciaram $(\mathrm{P}<0,05)$ a conversão alimentar $(\mathrm{CA})$ dos leitões no período de 21 a 35 dias. A CA dos animais que receberam a dieta com $0,84 \%$ de ácidos orgânicos foi melhor $(\mathrm{P}<0,05)$ que a daqueles que consumiram a dieta basal e com $0,90 \%$ de ácido orgânico e não diferiu da conversão alimentar daqueles que receberam a dieta $0,78 \%$. Isso evidencia o desafio a que os animais foram expostos, pois, mesmo com a inclusão do óxido de zinco em todas as dietas experimentais, o tratamento com 0,84\% de ácidos orgânicos foi mais eficiente, em razão da ação antimicrobiana.

Não houve efeito das proporções de ácidos orgânicos sobre nenhuma das características de desempenho avaliadas nos períodos de 21 a 49 e de 36 a 49 dias. No entanto, os animais que receberam 0,84 e $0,63 \%$ de ácidos orgânicos na dieta apresentaram aumento de 5,56\% no GPMD e melhora de $6,29 \%$ na CA no período total de 21 a 49 dias.
Vários pesquisadores (Giesting \& Easter, 1985; Palenzuela, 2000; Silva, 2004), avaliando a utilização de ácidos orgânicos em dietas para leitões, têm verificado efeito significativo dos tratamentos com ácido sobre sobre a conversão alimentar em relação ao grupo controle, sem efeito sobre o ganho de peso. No entanto, Silva et al. (2002) observaram melhora no ganho de peso médio diário dos leitões ao suplementarem a dieta com 2,5\% de ácido láctico, mas não notaram diferenças de consumo de ração e conversão alimentar em comparação ao tratamento controle. Também avaliando ácidos orgânicos nas rações de leitões, Risley et al. (1991), Teixeira et al. (2003) e Corassa et al. (2006) não verificaram variação no consumo de ração dos animais.

Tsiloyiannis et al. (2001ab), no entanto, fornecendo ácido láctico na dieta de leitões, observaram que os animais apresentaram melhora no ganho de peso, no consumo de ração e na conversão alimentar em relação àqueles do tratamento controle, demonstrando que o ácido orgânico tem efeito positivo sobre o organismo do animal como tratamento preventivo de doenças da fase pós-desmame.

Os resultados contraditórios dos trabalhos provavelmente ocorreram como conseqüência de fatores como a qualidade da ração fornecida aos animais. A dieta basal fornecida durante todo o período experimental foi composta de lactose, carboidrato utilizado pela microflora presente no trato digestivo, resultando na síntese do ácido láctico pelo processo fermentativo. Por isso, caso a dieta não fosse suplementada com lactose, o efeito do fornecimento de ácidos orgânicos poderia ser mais pronunciado.

Os valores do $\mathrm{pH}$ do estômago de leitões alimentados com dietas contendo $0 ; 0,78 ; 0,84$ e $0,90 \%$ de ácidos orgânicos no período de 21 a 35 dias de idade foram 3,$73 ; 3,79$; 3,60 e 3,61 , respectivamente.

Não houve efeito das proporções de ácidos orgânicos sobre o pH do estômago, resultado similar ao obtido por Silva (2004), que, trabalhando com ácido láctico e outros ácidos orgânicos, também não observou redução do pH no estômago dos leitões que receberam as dietas com os ácidos orgânicos. Entretanto, os resultados deste trabalho diferem dos apresentados por Thomlinson \& Lawrence (1981), que observaram diminuição do pH gástrico de leitões que receberam dietas com a adição de $0,8 \%$ de ácido láctico, em comparação à dieta controle.

É importante salientar que, como o pH é uma função logarítmica, mudanças aparentemente pequenas de $\mathrm{pH}$, na realidade, correspondem a variações grandes da concentração de $\mathrm{H}^{+}$. Assim, quando o $\mathrm{pH}$ varia de 0,3 unidade, a concentração de $\mathrm{H}^{+}$torna-se duas vezes maior; contudo, se 
Tabela 4 - Peso corporal inicial e final, consumo de ração médio diário (CRMD), ganho de peso médio diário (GPMD) e conversão alimentar (CA) dos leitões alimentados com dietas com diferentes proporções de ácidos orgânicos nos períodos de 21 a 35 , de 36 a 49 e de 21 a 49 dias de idade

Table 4 - Initial and final body weight, average daily feed intake (ADFI), average daily weight gain (ADWG) and feed:gain ratio (F/G) of piglets fed increasing dietary organic acids levels in the periods from 21 to 35 days, from 36 to 49 days and from 21 to 49 days old

\begin{tabular}{|c|c|c|c|c|c|c|}
\hline \multirow[t]{2}{*}{$\begin{array}{l}\text { Período } \\
\text { Period }\end{array}$} & \multicolumn{4}{|c|}{$\begin{array}{c}\text { Proporção de ácidos orgânicos (\%) } \\
\text { Organic acid proportion }\end{array}$} & \multirow[t]{2}{*}{ CV (\%) } & \multirow[t]{2}{*}{$\begin{array}{l}\text { Valor de } \mathrm{P} \\
P \text { value }\end{array}$} \\
\hline & 0,00 & 0,78 & 0,84 & 0,90 & & \\
\hline \multicolumn{7}{|l|}{$\begin{array}{l}21 \text { a } 35 \text { dias } \\
21 \text { to } 35 \text { days }\end{array}$} \\
\hline $\begin{array}{l}\text { GPMD }(\mathrm{g}) \\
A D W G\end{array}$ & 207 & 235 & 237 & 199 & 13,63 & 0,1106 \\
\hline $\begin{array}{l}\text { CRMD }(\mathrm{g}) \\
A D F I\end{array}$ & 273 & 288 & 263 & 274 & 15,48 & 0,5942 \\
\hline $\begin{array}{l}\text { CA }(\mathrm{g}: \mathrm{g}) \\
F / G\end{array}$ & $1,30 \mathrm{~b}$ & $1,23 \mathrm{ab}$ & $1,11 \mathrm{a}$ & $1,38 \mathrm{~b}$ & 11,15 & 0,0285 \\
\hline $\begin{array}{l}36 \text { a } 49 \text { dias } \\
36 \text { to } 49 \text { days }\end{array}$ & 0,00 & 0,59 & 0,63 & 0,66 & & \\
\hline $\begin{array}{l}\text { GPMD }(\mathrm{g}) \\
A D W G\end{array}$ & 408 & 408 & 414 & 424 & 10,90 & 0,7176 \\
\hline $\begin{array}{l}\text { CRMD }(\mathrm{g}) \\
A D F I\end{array}$ & 704 & 688 & 695 & 724 & 10,58 & 0,61037 \\
\hline $\begin{array}{l}\text { CA }(\mathrm{g}: \mathrm{g}) \\
F / G\end{array}$ & 1,72 & 1,69 & 1,68 & 1,71 & 7,24 & 0,9776 \\
\hline $\begin{array}{l}21 \text { a } 49 \text { dias } \\
21 \text { to } 49 \text { days }\end{array}$ & 0,00 & 0,78 e 0,59 & 0,84 e 0,63 & 0,90 e 0,66 & & \\
\hline $\begin{array}{l}\text { Peso inicial } \\
\text { Initial body weight }(\mathrm{kg})\end{array}$ & 5,63 & 6,05 & 6,08 & 5,78 & & \\
\hline $\begin{array}{l}\text { Peso final } \\
\text { Final body weight (kg) }\end{array}$ & 14,04 & 15,01 & 15,17 & 14,36 & & \\
\hline $\begin{array}{l}\text { GPMD }(\mathrm{g}) \\
A D W G\end{array}$ & 306 & 320 & 323 & 314 & 10,10 & 0,8459 \\
\hline $\begin{array}{l}\text { CRMD }(\mathrm{g}) \\
\text { ADFI }\end{array}$ & 489 & 488 & 479 & 499 & 10,01 & 0,6382 \\
\hline $\begin{array}{l}\text { CA }(\mathrm{g}: \mathrm{g}) \\
F / G\end{array}$ & 1,59 & 1,53 & 1,49 & 1,59 & 7,26 & 0,6560 \\
\hline
\end{tabular}

Médias seguidas de letras distintas na mesma linha indicam diferença significativa $(P<0,05)$ pelo teste Duncan.

Mean followed by different letters in a row differ $(P<0.05)$ by Duncan test.

varia de 3,0 , a concentração torna-se mil vezes maior (Vieira et al., 1995). Alterações do pH têm várias implicações fisiológicas no organismo do animal, comprometendo a atividade celular ao influenciarem as funções metabólicas essenciais (Halm et al., 2004), a síntese de DNA e RNA e a multiplicação celular (Silva, 2004).

Os dados de escore fecal dos leitões alimentados com as dietas experimentais nos períodos de 21 a 35 , de 36 a 49 e de 21 a 49 dias de idade são apresentados na Tabela 5 e na Figura 1.

Observou-se efeito $(\mathrm{P}<0,05)$ das proporções de ácidos orgânicos sobre o escore fecal nos dois períodos experimentais. Os leitões que receberam a ração com $0,84 \%$ de ácidos orgânicos no período de 21 a 35 dias apresentaram menor escore fecal em relação aos que receberam $0,90 \%$. No período de 36 a 49 dias, o escore fecal dos animais que receberam $0,63 \%$ de ácidos orgânicos foi menor que o daqueles que receberam $0,66 \%$ e a dieta basal. Esse resultado corrobora os obtidos por Tsiloyiannis et al. (2001b), que, utilizando 1,6\% de ácido láctico na dieta de leitões no período de 28 dias após o desmame, também observaram menor valor de escore fecal nos animais que receberam ácido na ração aos do tratamento controle. No entanto, os resultados deste estudo diferiram dos verificados por Silva (2004), que não constatou variação no escore fecal em leitões alimentados com acidificantes em relação ao controle.

Em todos as proporções de ácidos orgânicos, os leitões apresentaram diarréia nos primeiros dias após a chegada à creche, como resultado do estresse nutricional que sofreram. A recuperação dos leitões foi gradual, porém o tratamento com $0,84 \%$ de ácido láctico no período de 21 a 35 dias, promoveu a melhora dos animais em menor tempo. 
Tabela 5 - Escore fecal de leitões alimentados com dietas contendo diferentes proporções de ácidos orgânicos nos períodos de 21 a 35, de 36 a 49 e de 21 a 49 dias de idade

Table 5 - Fecal score of piglets fed increasing dietary organic acids levels in the periods from 21 to 35 days, from 36 to 49 days and from 21 to 49 days old

\begin{tabular}{|c|c|c|c|c|c|c|}
\hline \multirow[t]{2}{*}{$\begin{array}{l}\text { Período } \\
\text { Period }\end{array}$} & \multicolumn{4}{|c|}{$\begin{array}{c}\text { Proporção de ácidos orgânicos (\%) } \\
\text { Organic acid proportion }\end{array}$} & \multirow[t]{2}{*}{ CV (\%) } & \multirow[t]{2}{*}{$\begin{array}{c}\text { Valor de } \mathrm{P} \\
P \text { value }\end{array}$} \\
\hline & 0,00 & 0,78 & 0,84 & 0,90 & & \\
\hline \multirow{2}{*}{$\begin{array}{l}21 \text { a } 35 \text { dias } \\
21 \text { to } 35 \text { days }\end{array}$} & 0,00 & 0,78 & 0,84 & 0,90 & & \\
\hline & $2,7 \mathrm{ab}$ & $2,7 \mathrm{ab}$ & $2,6 \mathrm{a}$ & $2,9 b$ & 6,96 & 0,0086 \\
\hline \multirow{2}{*}{$\begin{array}{l}36 \text { a } 49 \text { dias } \\
36 \text { to } 49 \text { days }\end{array}$} & 0,00 & 0,59 & 0,63 & 0,66 & & \\
\hline & $2,5 b$ & $2,3 a b$ & $2,2 \mathrm{a}$ & $2,5 b$ & 8,03 & 0,01469 \\
\hline \multirow{2}{*}{$\begin{array}{l}21 \text { a } 49 \text { dias } \\
21 \text { to } 49 \text { days }\end{array}$} & 0,00 & 0,78 e 0,59 & 0,84 e 0,63 & 0,90 e 0,66 & & \\
\hline & $2,6 \mathrm{ab}$ & $2,5 \mathrm{ab}$ & $2,4 \mathrm{a}$ & $2,7 b$ & 6,67 & 0,0052 \\
\hline
\end{tabular}

Médias seguidas de letras distintas na mesma linha indicam diferença significativa $(P<0,05)$ pelo teste Duncan.

Mean followed by different letters in a row differ $(P<0.05)$ by Duncan test.

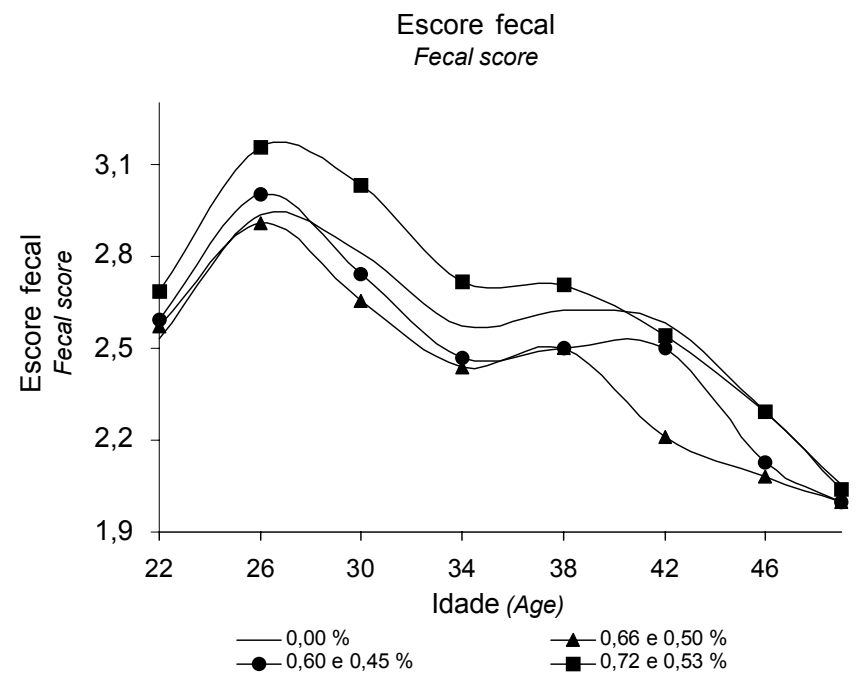

Figura 1 - Escore fecal de leitões alimentados com dietas com diferentes proporções de ácidos orgânicos no período de 21 a 49 dias de idade.

Figure 1 - Fecal score of piglets fed increasing dietary organic acids levels from 21 to 49 days old.
O aumento do trânsito intestinal, além de ser agressivo para a mucosa, comprometendo a absorção e, conseqüentemente, o desempenho animal, remove quantidades massivas de bactérias colonizadoras (Bongaerts et al., 2005), favorecendo a colonização de patógenos.

Os valores das concentrações médias de ácido láctico no trato digestivo e no sangue dos leitões aos 35 dias de idade são apresentados na Tabela 6 .

As proporções de ácidos orgânicos não influenciaram a concentração de ácido láctico no trato digestivo. No entanto, foi possível observar valores numéricos muito distintos entre as dietas com ácidos orgânicos e a basal. A região do trato digestivo dos animais com maior concentração de ácido láctico foi o estômago. Em todas as proporções, a concentração de ácido láctico reduzia à medida que a digesta avançava no lúmen intestinal, sendo menor a concentração no íleo, exceto na proporção de $0,90 \%$ de ácidos orgânicos, que ocasionou menor concentração de ácido no duodeno. Esse fato, no entanto, não tem explicação biológica aparente.

Tabela 6 - Concentração de ácido láctico $(A L)$ nas porções do trato digestivo e no sangue de leitões aos 35 dias de idade Table 6 - Concentration of lactic acid (LA) in the digestive tract and blood of piglets at 35 days old

\begin{tabular}{lccccc}
\hline $\begin{array}{l}\text { Concentração de AL (mg/dL) } \\
\text { LA concentration }\end{array}$ & \multicolumn{3}{c}{$\begin{array}{c}\text { Proporção de ácidos orgânicos (\%) } \\
\text { Organic acid proportion }\end{array}$} & CV (\%) & $\begin{array}{c}\text { Valor de P } \\
P \text { value }\end{array}$ \\
\cline { 2 - 6 } & 0,00 & 0,78 & 0,84 & 0,90 & 52,41 \\
\hline Estômago (Stomach) & 53 & 107 & 111 & 118 & 42,49 \\
Duodeno (Duodenum) & 56 & 75 & 75 & 33 & 42,78 \\
Jejuno (Jejuno) & 65 & 73 & 76 & 71 & 68,9367 \\
Ileo (Ileum) & 26 & 24 & 50 & 55 & 0,1448 \\
Sangue (Blood) & $33 \mathrm{a}$ & $47 \mathrm{ab}$ & $45 \mathrm{ab}$ & $53 \mathrm{~b}$ & 0,2880 \\
\hline
\end{tabular}

Médias seguidas de letras distintas na mesma linha ou na mesma coluna indicam diferença significativa $(P<0,05)$ pelo teste Duncan.

Mean followed by different letters in a row or in the same column differ $(P<0.05)$ by Duncan test. 
A concentração de ácido láctico no sangue dos animais que receberam as dietas com ácido orgânico não variou. Entretanto, a concentração de ácido láctico no sangue dos animais que receberam as dietas com $0,78 \mathrm{e}$ $0,84 \%$ não diferiu da dieta basal, mas a daqueles que receberam $0,90 \%$ de ácido $(\mathrm{P}<0,05)$ aumentou em $60,61 \%$ em relação ao grupo que recebeu a dieta basal. Esse excesso de ácidos orgânicos na dieta dos animais que consumiram $0,90 \%$ de ácido foi, provavelmente, o fator que piorou o escore fecal dos leitões.

As bactérias encontradas nas fezes dos animais, identificadas pelo exame bacteriológico, são representadas na Tabela 7.

A dieta basal retratou o desafio a que os animais foram submetidos. Entre as bactérias encontradas, destacou-se a E. coli $\beta$-hemólise, isolada das fezes de todos as proporções, o que coincidiu com o histórico da granja de doença do edema, diagnosticada por meio de sinais clínicos típicos e necropsia dos leitões. Silva (2004), trabalhando com ácido láctico e outros ácidos orgânicos, também observou a presença de E. coli, ao contrário de Tsiloyiannis et al. (2001b), que verificaram redução no número de $E$. coli $\beta$-hemolítica positiva nas fezes dos animais que receberam ácidos orgânicos no período de 28 dias após o desmame. A E. coli $\mathrm{K} 88^{+} \beta$-hemolítica pode diminuir a taxa de crescimento dos animais e, possivelmente, aumentar a mortalidade em decorrência da doença do edema e da diarréia pós-desmame (Pluske et al., 1997; Tsiloyiannis et al., 2001a).

As proporções de 0,84 e 0,63\% de ácidos orgânicos, respectivamente, nas fases de 21 a 35 e 36 a 49 dias, foram mais eficientes, considerando-se que não foram isoladas as bactérias E. coli a-hemólise e Streptococcus sp.

Tabela 7 - Exame bacteriológico das fezes de leitões alimentados com as diferentes dietas experimentais nos períodos de 21 a 35 e de 36 a 49 dias de idade

Table 7 - $\quad$ Feces bacteriological examination of piglets fed different experimental diets in the periods from 21 to 35 and from 36 to 49 days old

Proporção de ácidos orgânicos

Organic acids proportion (\%)

$$
\text { Período }
$$$$
\text { Period }
$$

$\begin{array}{cc}21 \text { a } 35 \text { dias } & 36 \text { a } 49 \text { dia } \\ 21 \text { to } 35 \text { days } & 36 \text { to } 49 \text { days } \\ 0,00 & 0,00 \\ 0,78 & 0,59 \\ 0,84 & 0,63 \\ 0,90 & 0,66\end{array}$

Agente isolado

Isolated agent

\begin{tabular}{ccc} 
& \multicolumn{1}{c}{$\begin{array}{c}\text { Agente isolado } \\
\text { Isolated agent }\end{array}$} \\
\hline E. coli $\beta$-hemólise & E coli a-hemólise & Streptococcus sp. \\
E. coli b-haemolytic & E. coli a-haemolytic &
\end{tabular}

E. coli a-haemolytic

Convenções adotadas: presença (+) e ausência (-)

Conventions: presence (+) and absence (-).

\section{Conclusões}

A utilização de $0,84 \%$ de ácidos orgânicos na dieta proporcionou melhor conversão alimentar em leitões no período de 21 a 35 dias e melhor consistência de fezes e controle de E. coli $\alpha$-hemólise e Streptococcus sp. com a suplementação de $0,84 \%$ de ácidos orgânicos no período de 21 a 35 dias e de $0,63 \%$ no período de 36 a 49 dias.

\section{Literatura Citada}

BONGAERTS, G.; SEVERIJNEN, R.; TIMMERMAN, H. Effect of antibiotics, prebiotics and probiotics in treatment for hepatic encephalopathy. Medical Hypotheses, v.64, Issue 1, p.64$68,2005$.

BURNELL, T.W.; GROMWELL, G.L.; STAHLY, T.S. Effects of dried whey and copper sulfate on the growth responses to organic acid in diets for weanling pigs. Journal of Animal Science, v.66, n.5-6, p.1100, 1988.
CORASSA, A.; LOPES, D.C.; OSTERMANN, J.D. et al. Níveis de ácido fólico em dietas contendo ácido fórmico para leitões de de 21 a 49 dias de idade. Revista Brasileira de Zootecnia, v. 35, n.2, p.462-470, 2006.

CURTIS, S.E. Environmental managment in animal agriculture 2.ed. Ames: Iowa State University, 1983. 410p.

DEAN, J.A.; LANGE, N.A. Lange's hand book of chemistry. 13. ed. [S. 1.]: McGraw Hill, 1985. 1424p.

GIESTING, D.W.; EASTER, R.A. Response of starter pigs to supplemetation of corn-soybean meal diets with organic acids. Journal of Animal Science, v.60, n.5, p.1288-1294, 1985.

GRAVESEN, A.; DIAO, Z.; VOSS, J. et al. Differential inactivation of Listeria monocytogenes by d- and 1-lactic acid. Letters in Applied Microbiology, v.39, Issue 6, p.528-532, 2004.

HALM, M.; HORNBAEK, T.; ARNEBORG, N. et al. Lactic acid tolerance determined by measurement of intracellular $\mathrm{pH}$ of single cells of Candida krusei and Saccharomyces cerevisiae isolated from fermented maize dough. International Journal of Food Microbiology, v.94, Issue 1, p.97-103, 2004.

JENSEN, B.B. The impact of feed additives on the microbial ecology of the gut in young pigs. Journal of Animal Feed Science, v.7, p.45-64, 1998. 
KNARREBORG, A.; MIQUEL, N.; GRANLI, T. et al. A. Establishment and application of an in vitro methodology to study the effects of organic acids on coliform and lactic acid bacteria in the proximal part of the gastrointestinal tract of piglets. Animal Feed Science and Technology, v.99, Issues 1-4, p.131-140, 2002.

ORLANDO, U.A.D.; OLIVEIRA, R.F.M.; DONZELE, J.L. et al. Níveis de proteína bruta para leitoas dos 30 aos $60 \mathrm{~kg}$ mantidas em ambiente de alta temperatura $\left(31^{\circ} \mathrm{C}\right)$. Revista Brasileira de Zootecnia, v.30, n.5, p.1536-1543, 2001a.

PALENZUELA, P.R. Los acidos organicos como agentes antimicrobianos. In: CURSO DE ESPECIALIZACIÓN, 11., 2000. [S. 1.]. Proceedings... [S. 1.]: Fundación Española para el Desarrollo de la Nutrición Animal - FEDNA, 2000. p.171-181.

PARTANEN, K.H.; MROZ, Z. Organic acids for performance enhancement in pig diets. Nutrition Research Reviews, v.12, n.1, p.117-145, 1999.

PLUSKE, J.R.; WILLIAMS, I.H.; AHEME, F.X. Nutrition of the neonatal pig. In: VARLEY, M.A. (Ed.). The neonatal pig: development and survival. Wallingford: CAB International, 1995. p.187-235.

PLUSKE, J.R.; HAMPSON, D.J.; WILliANS, I.H. Factors influencing the structure and function of the small intestine in the weaned pig: a review. Livestock Production Science, v.51, p.215-236, 1997.

PRESSER, K.A.; RATKOWSKY, D.A.; ROSS, T. Modelling the growth rate of Escherichia coli as a function of $\mathrm{pH}$ and lactic acid concentration. Applied and Environmental Microbiology, v.63, n.6, p.2355-2360, 1977.

RISLEY, C.R.; KORNEGAY, E.T.; LINDERMANN, M.D. et al. Effects of organic acids with and without a microbial culture on performance and gastrointestinal tract measurements of wealing pigs. Animal Feed Science and Technology, v.35, n.3-4, p.259-270, 1991.

Rostagno, H.S.; ALBINO, L.F.T.; DONZELE, J.L. et al. Composição de alimentos e exigências nutricionais de aves e suínos: tabelas brasileiras. Viçosa, MG: Universidade Federal de Viçosa, 2000. 141p.

ROTH, F.X. Ácidos orgánicos en nutrición porcina: eficacia y modo de acción. In: In: CURSO DE ESPECIALIZACIÓN, 11., 2000. [S. 1.]. Proceedings... [S. 1.]: Fundación Española para el Desarrollo de la Nutrición Animal - FEDNA, 2000. p.169-181.

SANTOS, M.S.; POZZA, P.C.; LIMA, S.A. et al. Avaliação da suplementação de mananoligossacarídeos e acidificantes em dietas para suínos fêmeas na fase de terminação. In: CONGRESSO BRASILEIRO DE VETERINÁRIOS ESPECIALISTAS EM SUÍNOS, 2003. Anais... Goiânia: ABRAVES, 2003. p.307-308.
STATISTICAL ANALYSIS SYSTEMS - SAS. User's guide: statistics. Cary: 1999.

SILVA, M.C.; LIMA, J.A.F.; FIALHO, E.T. et al. Efeito da adição de acidificantes e suas combinações na alimentação de leitões desmamados sobre o desempenho. In: REUNIÃO ANUAL DA SOCIEDADE BRASILEIRA DE ZOOTECNIA, 39., 2002, Recife. Anais... Recife: Sociedade Brasileira de Zootecnia, 2002. (05.sbz.993.pdf. 2002). CD-ROM.

SILVA, G.F. Digestibilidade ileal de aminoácidos de soja micronizada e de farelo de soja para suinos e avaliação de acidificantes em dietas para leitões. Viçosa, MG: Universidade Federal de Viçosa, 2004. 96p. Dissertação (Mestrado em Zootecnia) - Universidade Federal de Viçosa.

TEIXEIRA, M.P.; SILVA, G.F.; LOPES, D.C. et al. Avaliação de ácidos orgânicos e inorgânicos em dietas para leitões desmamados aos 21 dias de idade. In: REUNIÃO ANUAL DA SOCIEDADE BRASILEIRA DE ZOOTECNIA, 40., 2003, Santa Maria. Anais... Santa Maria: Sociedade Brasileira de Zootecnia, 2003. (CD-ROM)

THOMLINSON, J.R.; LAWRENCE, T.L.J. Dietary manipulation of gastric $\mathrm{pH}$ in the prophylaxis of enteric diseaese in weaned pigs: some field observations. Veterinary Record, v.109, n.1, p.120-122, 1981.

TSILOYIANNIS, V.K.; KYRIAKIS, S.C.; VLEMMAS, J. et al. The effect of organic acids on the control of post-weaning oedema disease of piglets. Research in Veterinary Science, v.70, p.281-285, 2001a.

TSILOYIANNIS, V.K.; KYRIAKIS, S.C.; VLEMMAS, J. et al. The effect of organic acids on the control of porcine post-weaning diarrhoea. Research in Veterinary Science, v.70, p.287293, 2001b.

TZIPORI, S.; CHANDLER, D.; MAKIN, T. et al. Escherichia coli and rotavirus infections in four-week-old gnotobiotic piglets fed milk or dry food. Australian Veterinary Journal, v.56, n.1, p.279-284, 1980 .

VIEIRA, E.C.; FIGUEIREDO, E.A.; LEITE, J.I.A. et al. Química fisiológica. 2.ed. São Paulo: Atheneu, 1995. 414p. 